First Peoples Child \& Family Review

A Journal on Innovation and Best Practices in Aboriginal Child Welfare Administration,

Research, Policy \& Practice

\title{
COMMENTARY: Knowledge Mobilization in the Real World - Seeking Wisdom
}

\section{Jean Lafrance}

Volume 4, Number 1, 2009

URI: https://id.erudit.org/iderudit/1069352ar

DOI: https://doi.org/10.7202/1069352ar

See table of contents

Publisher(s)

First Nations Child and Family Caring Society of Canada

ISSN

1708-489X (print)

2293-6610 (digital)

Explore this journal

Cite this document

Lafrance, J. (2009). COMMENTARY: Knowledge Mobilization in the Real World -

Seeking Wisdom. First Peoples Child \& Family Review, 4(1), 80-88.

https://doi.org/10.7202/1069352ar viewed online.

https://apropos.erudit.org/en/users/policy-on-use/ 


\title{
COMMENTARY: Knowledge Mobilization in the Real World - Seeking Wisdom
}

\author{
Jean Lafrance ${ }^{a}$
}

a PhD, Associate Professor, Faculty of Social Work, University of Calgary, Edmonton, Alberta, Canada

What is it that keeps us from acting on knowledge that we believe to be true? Over the years, mankind has derived many different forms of knowledge from science, from experience, and from divine revelation. We have applied some forms, especially in the natural sciences, to immense benefit to humankind, but other forms, especially in the human sciences, seem more difficult to apply. In the more recent past, we have had the benefit of considerable research to help us better understand how many of our societal problems are rooted in fundamental inequalities in our society. This polemic will focus important considerations in our search for better ways to serve our brothers and sisters. These include our knowledge of the social determinants of health, attachment theory, childhood resiliency, the impact of poverty, racism and its accompanying oppression. Few can deny that these are important factors in the development of healthy families that can form and nurture healthy and productive members of our society. Their relevance to the world of program and services seem obvious, yet they are remarkably elusive in their application I do not have easy answers to this conundrum, but I do wish to pose some provocative questions that will hopefully encourage a deeper reflection on these matters and open our minds to new possibilities that can assist us in pursuing their application Ultimately, if we define wisdom as the ability

Questions or correspondence concerning this article may be
addressed to:
Jean Lafrance, PhD
Associate Professor
The University of Calgary
Faculty of Social Work
11044 82 Avenue
Edmonton, AB
Tel: (780) 491-3889
il3@ucalgary.ca

to put knowledge into purposeful action, we may even come closer to achieving wisdom.

\section{Social Determinants of Health}

Richard Wilkinson, a leading researcher in the area of health inequities, has summarized the most critical social determinants:

\begin{abstract}
Most important are three intensely social risk factors. First is low social status, which in this context is less a matter of low material living standards themselves than of their social consequences, such a feeling looked down upon, having an inferior position in the social hierarchy, and subordination (and therefore also a reduced ability to control one's circumstances and work). Second comes poor affiliations of all kinds, including lack of friends, being single, weak social networks, lack of involvement in community life, and so on ....Third comes early childhood experience which prepares us to deal with more conflict-ridden or more affiliative social environments. (As cited in Understanding the Social Determinants of Health, 2006)
\end{abstract}

In his book Mind the Gap: Hierarchies, Health and Human Evolution Richard Wilkinson (2001) provides a novel approach to the question of inequity and perhaps inadvertently repeats an observation that Aboriginal people made in their initial encounters with the French, whom they considered barbaric because of their tolerance of poverty among them, something that no Aboriginal community would have accepted. Wilkinson points out that such inequality is new to our species, and began only when human societies became hierarchical about ten thousand years ago. In his penetrating analysis of patterns of health and disease, Wilkinson concludes that rather than relying on more police, prisons, social workers, or doctors, we must tackle the corrosive social effects of income differences in our society. 
The May 2009 report of The Office of the Auditor General of Canada makes it clear that ... "many First Nations face difficult socio-economic conditions. Some communities are in crisis. According to First Nations, these conditions present different challenges for First Nations than for mainstream society, but are not taken into account in the child welfare system. There is also a need to address the underlying causes of child welfare cases" (Chapter 4, p.16.)

The inevitable question for all of us is "What keeps us from acting on this knowledge?"

\section{Structural Poverty}

The social determinants of health indicate that poverty is a major contributor to many difficulties that families experience. Much of the literature on child welfare suggests that there is a high correlation between poverty and the likelihood of a child ending up in the child welfare system,

There is little doubt that children who are born in poor families, whose lives begin in an environment of deficiency and whose parents are preoccupied with the stresses of being able to provide decent accommodation, food, and security are at far greater risk than children whose parents are financially secure. Yet we have failed as a society to ensure that every child receives a basic level of sustenance, often blaming their parents for their deficiencies - all the while forgetting that these parents were raised within a similar situation. This is not to suggest that all poor children are doomed to the same eventuality, as some can overcome this burden at great personal effort, but we do know that there's a much higher possibility that this will be the case.

We have failed to deal with the broad structural problems that produce poverty. Inequity, marginalization, and powerlessness aggravate poor families' distress. There has been too great a reliance on traditional micro perspectives on children's well being. In other words, we make every effort to "fix" the people who present themselves for our help and too little to remedy the conditions that bring them to us. The capacities of families to meet their responsibilities to children are heavily influenced by the structural conditions available to parents such as sustaining jobs and being able to raise their children in adequate and affordable accommodations. Poor families are associated with high levels of transient living, sub-standard housing, lower education, poor nutrition, high rates of substance abuse and emotional disorders, and inadequate social support systems. In turn, poverty is the factor that places children at greatest social risk. Child poverty is not a directly causal factor, of course, but the correlation of poverty with other factors such as single parenthood, social isolation, and unsafe neighborhoods can enormously increase risks to children. While most poor families do not neglect their children, child welfare systems draw upon the families of the poor - the point raised by Kinjerski and Herbert (2000) and in the annual reports and in public forums by Alberta's Children's Advocate.

Leschied et al. (2003) summarize some important elements of the literature relating poverty to child outcomes reflects three major themes. The first theme relates child development directly to factors intrinsic to families living in poverty. These studies include factors such as nutrition and brain development suggesting poverty and, specifically, poor nutrition, places children at risk for later learning, behavioural and developmental challenges (Galler, Ramsay, Solimano \& Lowell, 1983; Mustard, 1999; Tanner \& Finn-Stevenson, 2002).

A second theme suggests that the instability of living arrangements and homelessness due to poverty place children at increased risk (Bassuk, 1996; Bassuk et. al., 1997). This may reflect the inability of children to receive consistent educational opportunities and parent(s) to develop a social network of support to buffer parental stress. Kowaleski-Jones (1999) suggest that families in 'deep poverty' 5 , have increasing difficulties exiting low income due low education levels and inadequate day care that are necessary to create a link to employment opportunities. This is of particular relevance to families involved with the child welfare system since, as noted by Trocmé et al. (2001) child maltreatment in Canada is particularly related to "... the major environmental conditions of which low socio-economic status and housing conditions play a significant role" (p. 29).

Thirdly, Avsion et al. (1994) provide a more encompassing framework within which to view the effects of poverty on children. They suggest that the 'pernicious' effects of poverty are such that the financial strain results in the combined effects of caregiver strain, lack of social support, lowered self-esteem and maternal distress resulting in childhood vulnerabilities reflected in both internal and external problems.

The extreme poverty of children in Canada requires no elaboration in this journal. The problems are even more serious in Aboriginal families. Wein and colleagues (2007), found in the Canadian Incidence Study that the most important reason for Aboriginal children coming into care was physical neglect, meaning that in many cases parents were unable to properly care for them because of their poverty, and the concomitant issues of poor housing and problems with addiction.

Of course, there is much we do not know about the effects of poverty and its interactivity with other factors. Why, for example, are some poor children successful while others fare poorly? What are the precise pathways or mechanisms by which poverty (income and other aspects of poverty) have positive or negative effects on children's 
development? What are the risk and protective factors for the physical and mental health (including chronic problems such as depression or substance abuse), and cognitive, linguistic, affective, and social development of children growing up in low-income families? How, in the context of poverty, do societal norms shape children's socioemotional characteristics and, in turn, influence children's socio-emotional and cognitive development? How does poverty interact with other variables, such as family structure and family processes, or ethnic and cultural differences, resulting in particular child outcomes? How do social-ecological - including neighborhood, family, and peer group - factors affect the development of poor children? To what extent does geographical mobility due to economic needs influences the stability and quality of housing and schooling and, consequently, children's developmental trajectories? Which interventions are most effective in reversing these impacts? What is the optimal timing for interventions and under what conditions?

Having said this, there is much that we do know about the pernicious and ongoing effects of poverty on child and family life. The question is - do we have the will to do something about it?

\section{Attachment Theory}

We know that children who do not have the fortune to develop a sound attachment and secure base at an emotional level with the mother, especially in the womb and during the first year of life are at an immense disadvantage, one that can be difficult to recoup. Yet we too often fail to ensure that pregnant mothers are provided with the security they need to prepare themselves the most important job in the world, that of producing the next generation of human beings. Yet in spite of knowing that the social circumstances of children can determine their present and future health, knowing that the happiness and contentment and security of the mother has a huge effect on determining the future emotional and physical well-being of the child, knowing that we have a limited time and opportunity to ensure that young children are able to develop to the fullest extent, we continue to fail many of our children.

Nowhere is this more visible than in the world of Child Welfare which deals with children who are most likely to have experienced such losses; children who are most likely to have lacked the fundamental security and firm foundations that all of us depend upon to live rich and fruitful lives. Nowhere is this more likely to happen than with children whose basic needs for security, love, food, attention, and attachment have not been met. Nowhere is this more likely to occur with than with children who live with a series of unrelated caregivers, whose love and emotional attachment may be peripheral at best. Nowhere is this more likely to occur than for Aboriginal children who in addition to the burden that they carry as a result of their early backgrounds, have to carry the burden of losing their identity, their sense of self, and their connection to family, community and culture. The evidence seems clear that for too many of these children, life becomes a revolving door of renewed poverty, homelessness, addiction, institutional life in jails and mental health settings. This we know to be true. The question then becomes, why are we failing to address the fundamental root causes that produce such devastation upon our children and upon our world? Why are we are reluctant or unable or unwilling to act upon the information that we have. We continue to develop new information, new research and are probably the most researched people humanity has ever known. Some have defined wisdom as the ability to apply knowledge into practice. This is especially difficult today as we sift through massive amounts of information derived from the internet, magazines, books, blogs, and many other forms of media. The question is, when does such knowledge become wisdom? To what extent does all of this information serve to improve the human condition and the creation of a more egalitarian, humanistic and ultimately spiritual society that will attend to the needs of all of its members.

While this discussion is focused on the Indigenous people of Canada, it seems clear that Indigenous people everywhere are suffering. As a human race, we know that twenty percent of our members are consuming eighty percent of the world's resources. We know that we are devastating Mother Earth in our practices, fouling its waters, polluting its air. We know that there are fundamental racist and oppressive attitudes towards others, particularly towards those with a darker shade of skin. We know that many of our mainstream institutions depend upon a constant supply of such people to maintain their existence. Our courts, our legal systems, our police forces, our jails depend upon a constant and increasing supply to keep their jobs. Yet based on the evidence in this country and in the United States, we should by now have come to realize that the solutions do not lie in the arrest, processing, and incarceration of poor black men, poor Native men, and poor Hispanic men. The evidence seems clear that the solutions sought by the Bush administration and now likely the Harper administration will not address the problems and the issues that are ahead of us. The child welfare system is not too different. Were it not for poor Aboriginal families, it would be far smaller that it is today. Sadly, with growing immigration from African countries, I worry that we are following similar trends as in the US with Black children whose families are increasingly coming to the attention of the authorities

\section{How did we get here? A Societal Conundrum}

John Ralston Saul, when he wrote "Voltaire's Bastards", described how over many years, the common people had 
given over the authority to their kings as being in the best position to make decisions or judgments on their behalf. This worked more or less well for many years, until the French Revolution decided that the people had had enough of a royalty that showed no concern for the people who were starving in the streets. Ralston Saul then speaks of a shift in thinking that assumed that such power could better be placed in the hands of those we might now call technocrats; highly educated individuals who were prepared to assume leadership roles in dealing with important social issues and develop solutions based on a their superior knowledge and competence. This then, would be our basis for our safety; the intelligence of others. In some ways, this resulted in positive outcomes, and in many western countries the foundation was set for the creation of fundamental safety net systems for the old, the poor, for the creation of health care systems that would cover everyone, the creation of educational systems that would be able to serve all those that were interested and so on. Yet even then, some worried about this assumption. Eduard Lindeman spoke eloquently at the end of the 19th century about

$$
\begin{aligned}
& \text {.. Technologists and specialists insulating } \\
& \text { themselves from the folk process and becoming } \\
& \text { each in his own limited sphere, wise in } \\
& \text { particulars and ignorant in general. (Lindeman, } \\
& \text { 1948, p. 304) }
\end{aligned}
$$

Many would agree that the health, education, legal, and social institutions that serve people are failing them, especially those that serve Aboriginal people, despite the outlay of immense expenditures of money, time and human resources. Some speak of the misery industry - that which lives off the misery of the poor and the oppressed. A phenomenon is not easy to discount. If one were to add up of the resources allocated to Aboriginal people in Canada, including direct and indirect services and benefits, it would surely add up to billions of dollars. The capacity of clients, communities, and front line service providers to influence and fundamentally, change the institutions that have taken control of the lives of Aboriginal people seems limited at best. In part, the continuing and inexorable growth of such institutions can be attributed to their inherent to preserve themselves at all costs. Like any organism, whatever else they aspire to, all humanly created institutions primarily wish to preserve themselves. To achieve this purpose, along with their many reasons for existence, institutions must be highly organized to achieve these with efficiency and effectiveness. While this may have advantages, not the least of which is that organizations could not function without them, there are some inevitable downsides. This calls for top down direction, precise procedural direction, rigid roles, and expectations in a highly organized bureaucracy, and loyalty to the top. Weber wrote of the evolution of an iron cage, a technically ordered, rigid, dehumanized society, when he speculated on the other future possibilities of industrial systems. Weber had a foreboding of an "iron cage" of bureaucracy and rationality, but he recognized that human beings are not mere subjects molded by sociocultural forces. We are both creatures and creators of socio-cultural systems. Moreover, even in a socio-cultural system that increasingly institutionalizes and rewards goal oriented rational behavior in pursuit of wealth and material symbols of status there are other possibilities.

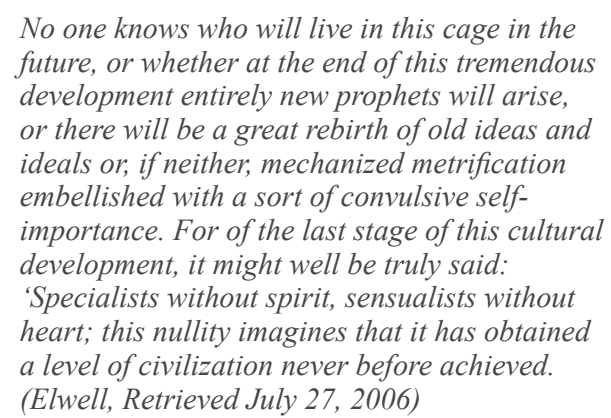

Even early social workers were becoming concerned about such a trend, as the organizational model became prevalent in the provision of social services.

\section{Philanthropy is becoming a business and a profession, and social agencies have begun to shut away the layman from any active connection with their function, crushing him beneath a magnificent and thoroughly perfected machine. (Winslow, 1915)}

"Humanity is acquiring all the right technology for all the wrong reasons. " (Buckminster Fuller)

The formation of such systems and their imposition on Aboriginal people who valued consensus, mutual respect and obedience to leaders based on their integrity as opposed to values that promoted top down and imposed leadership, the imposed authority of rank and hierarchy, and structured obedience that could be reinforced by punishment has created an inherent value conflict that continues to this day.

The extension of these inherent attitudes can be transmitted to those who serve such institutions, and whose loyalty is integral to the achievement of organizational purposes. In other words, in any contest between the purposes of the institution - be it a Federal Ministry such as INAC, a provincial organization such as Corrections, a local service such as Education - staff at all levels know what has the highest call on their loyalty, and what the penalties are for even appearing to favour those whom the organization is mandated to serve. We can see this at times even in the interaction between child welfare systems that serve and support Aboriginal families and to protect their children, creating the potential for conflict when staff disagrees with agency policy. 


\section{Knowledge Mobilization in the Real World - Seeking Wisdom}

\section{Aboriginal Mothers and Child Protection}

Three recent studies about the experiences of Aboriginal mothers with the child welfare system in British Columbia, in Manitoba and one continuing study in Alberta raise critical information about the relationship of mainstream child welfare systems with the mothers. These studies are a powerful testament to the distance we have yet to travel in our work with Aboriginal families and their communities. This is not to imply that immense efforts are underway nor is it to denigrate the efforts of so many policy makers, program planners, and committed staff to improving the service system for Aboriginal people, who are still the primary client. Many efforts are underway to address the programmatic factors that contribute to the hemorrhage of Aboriginal children to the child welfare system, but these will take many years to have the desired effect. While important policy and legislative changes support greater autonomy for Aboriginal child welfare programs in the recent past, we are suggesting that this is an essential, but not sufficient condition for improving the lot of Aboriginal families in the short term.

For those who would deny the possibility of this being necessary, we need look no further than the experience of Aboriginal mothers in three of our provinces where the numbers of Aboriginal children in care are reaching epidemic proportions. These studies include Broken Promises in B.C. (Pivot Legal Society, 2009), Jumping through the Hoops in Manitoba (Bennett, 2009), and Broken Hearts in Alberta (source?). While we cannot generalize this information there are sufficient commonalities in the experience of Aboriginal mothers in three western provinces to suggest that this it calls for closer examination. The triangulation of data from three different settings adds credibility sufficient to serve as caution - just like a dying canary in a mine warns the miners of toxic gases that may soon overwhelm them.

The Broken Promises study attributes much of this experience to a parent's struggle with poverty, addiction, mental health issues, or family violence:

- Poverty: Inadequate income assistance rates, the lack of safe and affordable housing, costly public transit, and inaccessible childcare all negatively impact the ability of poor women to care for their children.

- Mental health: People with mental health diagnoses and/or learning disabilities face discrimination as parents. Additional supports would assist them in caring for their children.

- Domestic violence: Women survivors of violence are poorly supported and, at times, re-victimized by the child protection system, which sees them as making poor choices, and failing to protect their children.
- Drug and alcohol use: There is an urgent need for enhanced treatment and harm reduction options for mothers struggling with addiction.

The child protection system is purported to be oriented toward family supports and ensuring the best interests of the child. There have always been swings in the relative priority of family-centered versus child-centered practice, with the latter often following media driven crises when a child unfortunately dies while in care or under investigation. We now seem to be in that part of the cycle where we think it best to err in on the side of caution following extended periods of public criticism in each of these provinces, and this may well have a bearing on what on the face of it, seems to be abysmal social work practice with aboriginal families.

Thefollowing summarizes somemorenoteworthy findings that seem familiar in each of the reported jurisdictions.

- The web of surveillance: Mothers living in poverty are subject to a high degree of scrutiny by the Children's Ministries by other government ministries and by the public. As a result these mothers experience stress and distrust and may be reluctant to reach out for help in times of need, particularly when they believe that disclosing their personal difficulties could result in their worst fear - the removal of their children.

- Transparency: Parents are deprived of basic information related to their case at every stage of the child protection process. Being informed about the Ministry's concerns is crucial for parents to be able to take steps to improve their circumstances and work towards the return of their child. Parents reported that they were not informed that an investigation was underway, or of the steps they need to take to have their children returned. Despite the duty of social workers to keep parents informed about the status of their file and the plan for their child, mothers felt they were consistently uninformed and sometimes given misinformation.

- Placements and visits: Children taken into care were often placed far from their family, siblings, and community, often in culturally inappropriate homes. Parents and grandparents were also concerned about the low priority placed on ensuring visits with children, the way in which visits were supervised, and the lack of accountability when visits are cancelled. A number of parents are very upset about the quality of care their children are receiving and the Ministry's lack of responsiveness when they voice their concerns. The preservation of kinship ties and a child's attachment to the extended family was, in many cases, not observed. 
- The role of the social worker: Social workers must play a dual role that can be highly problematic in terms of their relationship with parents. They play a supportive role where they are expected to build trust with a parent and provide the appropriate services and resources. On the other hand, they are investigators who may eventually make the decision to apprehend or not return a child. These competing roles can impede trust or rapport between the parent and social worker. There is also a very high turnover rate among social workers, which creates a lack of continuity. Huge caseloads can make it impossible to respond quickly to changes in parents' lives or to appreciate the strides parents are making to address the Ministry's concerns.

- The court system: The Courts play an important role in the child protection system as decision-maker and reviewer of child protection cases. Parents describe the court system as not only overwhelming in its complexity, but also plagued with inordinate and unreasonable delays. Many parents reported that while they had legal representation they did not feel adequately informed of what to expect at court dates and often did not understand what had happened in court. Delays throughout the court process leave many parents feeling hopeless and unheard. The court system, intended as an oversight mechanism to ensure that child protection laws are being applied appropriately, is viewed by parents as doing too little too late.

\section{Outcomes for Children}

Taking children into government care in order to ensure their safety and well-being is not working. Outcomes for children coming out of the foster care system are devastating. The Broken Promises Report indicates that seventy-three percent of youth involved with the young offenders system in B.C. are also involved with the child protection system, only 21 percent of former youth in care graduate, compared with 78 percent of the general population, and that in B.C., young women who are in the permanent care of the province are four times more likely to become pregnant than other young women who have never been in care. When these children become parents, they disproportionately lose their own children to the foster care system. Sixty-five percent of the parents that took part in this study spent time in the foster care system themselves as children. While such statistics are not easily attainable in other provinces, it is not a stretch to conjecture that they would not vary greatly in the rest of Canada.

\section{How Could this be Happening?}

The inevitable question in my mind is how could a system established with the express purpose of supporting
Aboriginal families and protecting their children commit such atrocities? While this is a difficult subject to raise in this country, could it be at least in part because of systemic racism to which many of us are blind. Lise Noel (cited in Henderson, 2000, p.29) reminds us that systemic colonization is grounded in intolerance. This intolerance comes from unconscious assumptions that underlie "normal institutional rules and collective reactions." It is a consequence of following these rules and accepting these reactions in everyday life. In systemic colonization, Noel suggests that no single source of oppression or demeaning can be assigned causal or moral primacy. These are imbedded in the consciousness of all and so ingrained in our day-to-day lives that if the oppressed cannot point to any single form of oppression, then the oppressor and his consciousness become invisible. There is little reason to believe that such attitudes are not deeply ingrained in child welfare as it is in most of Western society. Such attitudes will take a long time to change. Indeed, a superficial review of history might lead even the most optimistic of us to conclude otherwise.

Our challenge is to willing to confront our own contribution to the challenges encountered by Aboriginal families in dealing with complex institutions like child welfare and the court systems. This calls upon each of us to be prepared to look deep into our souls to root out the vestiges of racist attitudes that continue to confound our relationships. Young (cited in Henderson, 2000, p.30) poses a conundrum for those who belong to the dominant groups of society.
The oppressor has no apparent existence. Not only does he not identify himself as such, but also he is not even supposed to have his own reality. His presence is so immediate and dense and his universe coincides so fully with the Universe that he becomes invisible. Rarely seen, rarely named, he is unique nonetheless and having a full existence as the keeper of the word. He is the supreme programmer who confers various degrees of existence on those who are different from himself... as the embodiment of the universal, the dominator is also the only Subject, the Individual, who never being considered to belong to a particular group can study those impersonal categories of the population who pose a "problem", represent a "question", constitute a "case" or simply have a condition".

The complexities involved in reconciliation with Aboriginal people by members of the dominant group are no simple matter. To support Aboriginal self-determination in the development of policies and practices that are in keeping with Aboriginal traditions and beliefs calls for an uncommon degree of humility and a high degree of receptivity to different ways of thinking. It also calls for us to look into our soul, and as Carl Jung stated "People will do anything, no 
matter how absurd, in order to avoid facing their own soul." What are we afraid to find if we look into our souls?

\section{Looking Into Our Souls}

What is it that stops us from fearlessly addressing issues fundamental to human dignity and respect for individuals?" I propose that it is a corroding fear that inhibits creativity and the purposeful use of relationship to support families and their children. Combine thus with leadership that is prone to overreaction and a tendency to engage in damage control for public relations purposes, and we create an environment that is not conducive to facing problems honestly and openly. Without transparency, we are unlikely to resolve our most critical problems, proceeding, like the White Rabbit in Lewis Carroll's book, Alice's Adventures in Wonderland, with great haste to get absolutely nowhere. A first step has to be an ability to acknowledge our mistakes and to learn from them, rather than to "massage' the truth in the vain hope of sustaining public confidence. My ongoing monitoring of crises in child welfare all over the Western world makes it clear to me that this is not working.

Our work in Alberta under the Knowledge Mobilization Initiative raises some compelling issues. Front line child welfare workers plead to have their leadership assume greater responsibility in educating the public about the realities of their work, and to acknowledge that they will never be able to avoid the occasional situation that occurs in spite of their best efforts. They hope for a work environment that will permit them to create healthy relationships with the families they serve, and are often blocked by procedural and technological barriers from giving these priority. Often, their leaders, having little or no understanding what they are trying to achieve on front lines, fail to provide them with sufficient flexibility to be creative in their response to the families they serve, leaving them with rigidly structured responses to complex situations in a perpetual fear of litigation and blame when matters go awry.

Families expect respect and dignity, and to be involved in the articulation of their problems and what to do about them. More often, they are subjected to a veritable army of helpers, each with their own specialty, who want only a small part of their lives. However, no one wants to hear his or her whole story - there is no time! It seems as if Aboriginal mothers are the most oppressed and diminished people in our society. Yet they are the most critical component of the child welfare system. How often do we ask them what they need? Moreover, when we do, as occurred in these studies, how often do we listen?

Aboriginal Communities have been very articulate about their vision. The challenge is to learn from joint efforts with Aboriginal communities that will not only create new insights, but results in knowledge that is readily applied to real world situations. The current project took up this challenge by aiming to build collaboration among child welfare stakeholders and Aboriginal communities to examine issues relating to child welfare in their communities and create innovative, effective and practical approaches to child welfare that are more in keeping with traditional Aboriginal worldviews and may contribute to reconciliation, healing and increased community capacity. Community meetings have revealed that:

- There is a clear understanding of the current and past issues and their impact on community and family life.

- To address these issues will call forth the strength of the people based on the continuity of their culture, kinship systems and tribal responsibilities.

- It is essential to institute a structure that supports kinship relational roles and responsibilities, as the continuity of kinship is the key to well-being and survival, and

- The basis of their identity.

While there is progress, the communities' views of services that would help them, with some exceptions they are still removed from prevalent models of practice

\section{The More Things Change, the More they Remain the Same}

Yet, review after review concludes that with improved training, technology, and procedures we can in fact declare that no child well ever die in care again. If we can find the right model, if we import another solution from elsewhere, if we make child welfare workers more accountable, if we can get more resources, if we can organize more efficiently and effectively, if we can generate the right form, if we can land on the right organizational model and so it goes. If anyone is interested, I still have an audio tape of a press conference held by Dr. Neil Weber in 1984 declaring that since Alberta Social Services and Community Health was decentralizing and regionalizing its service system we would never have another Richard Cardinal again. I cannot count the number of reorganizations that have taken place in Alberta since that time, and I can see that our colleagues in other places have followed the same philosophy. Many more re-organizations later, we still proclaim that this time we will get it right. So what is the primary emotion that lies underneath all these efforts to get things right - to ensure that the child welfare system will never again have to read the headlines that proclaim the death of another child that it was supposed to protect? I propose that it is FEAR.

In part, the broader environment hones our reactions. The Homeland Security organization in the United States reflects a growing trend, one that opts to deal with fear of attack from within and without by building fences It is a 
return to building castles surrounded by moats or another Great Wall of China make us feel more secure. It is a fool's illusions. A recent conversation with a bio-chemical specialist from the U.S. revealed that all of these efforts are for naught. He described how by imbuing a small piece of blocking paper with a certain chemical that could be carried in your purse or wallet without attracting any attention, had sufficient force when dropped in the city water system to poison the entire water system and easily destroy all of it's inhabitants. How can we defend ourselves from such weapons? We give up basic freedoms when we subject ourselves in airports intrusive and ridiculous rules that keep expanding and building a security industry designed to make us feel safe. We live in a society where nearly half of all adults depend upon prescribed drugs to deal with their anxiety. I am told that anxiety is the most prevalent reason for the referral of children for mental health counseling. I hear people in all walks of life who are fearful of their employers and worry about the security of their jobs.

Our governments collude in raising alarm about growing crime with the public that is not supported by statistics. This does not mean that crime has disappeared. Native gangs in our major cities keep growing, spawned in jails that are populated alienated youth. This phenomenon will not go away until they belong to their communities, see a future for themselves and have hope for the future. This is the largest growing population in our country and it is a worrisome trend. However, will we really feel safer by hiring more police, sending more youth to court, and by filling our jails, an excellent training ground for future criminals? How long will it take to understand that the needs of these youth are rooted in those fundamental issues described earlier? If, as my friend Will Campbell, a spiritual advisor with Native Counseling Services of Alberta tells me, seventy-five percent of the men that he deals with in the jails are products of the Child Welfare system, should we not take the time to reflect on what we're doing and think of a different way? Would it be so difficult as a starting point to ensure that young mothers are secure and protected while their child is in the womb and to help them lay the foundation for life for their little ones? Would it be so difficult to use our knowledge, technology, and resources, to ensure that all families have a basic level of subsistence, that no child goes hungry, that all families have a decent home that no child goes to school feeling insecure and rejected and unloved? Can we not ensure that the collective resources of our society be available to all of our children so they can grow into happy, fulfilled and productive citizens?

You may ask, what would you have us do? This is too complicated, too expensive, and too hard! But, is it really? If we have the will, we can produce the material resources, knowing that we will pay a much higher price down the road if we hesitate. We know how to create strong and resilient children. A child who has one person in their life who values them and respects them can makes all the difference between a failed life on the street or in jail, or the life of a strong, capable individual, better prepared to face life on life's terms. Is it so difficult to ensure that every child has one person? We know that a child who can contribute to the community will have more respect for that community, feel more attached to it, more loyal to it and will want to contributing to that community with a greater sense of self-respect and belonging. Is it so difficult to ensure that children can contribute something to their community, to their school, to their church? We know that children who have some form of spiritual or religious connection will do far better in life Is it so difficult to ensure that every child has that opportunity? We know that every child who has the opportunity to develop one talent, to have one thing at which they can say, "I am very good at this, I am a good dancer. I am guitar player. I am a good soccer player". Anything that gives the child a sense of competence will help prepare the child for life on life's terms. Is this so difficult? We know that children who have an opportunity to engage in organized recreation are far better prepared to live life on life's terms. The lessons learned about teamwork and socialization, respect for others, competition, channeled aggression are invaluable. A life lived on life's terms. If this is so simple, why can we not do it? Why do we have to keep searching for other solutions? Why do we keep tinkering around the edges? Why do we have so much trouble changing our minds in the face of so much evidence that what we do now is not working? The answers are clear and if we take this one step at a time and one child at a time, we can make a difference. The essence of child welfare has not changed very much over the past 200 years. We have to think about what is working and what is not. We need the courage to discard what is not working and do more of what does. Simple. The catch is that one of the hardest things to change is our minds. If we can do that, the rest is clear sailing.

\section{The Right Path}

I believe that we have lost our way. Carlos Castaneda asks his Shaman "How does one know if he is on the right path? The Shaman replies,

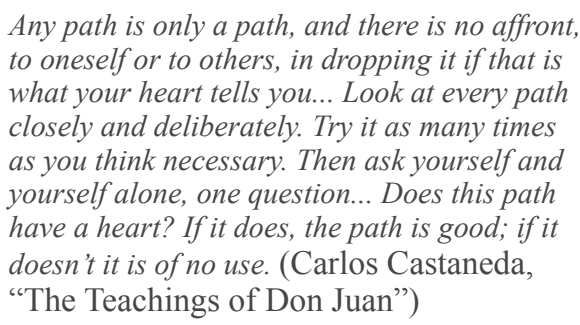

The question is for us, "Does our path have a heart?" I believe that we need to learn how to take the Red Road. 


\section{Knowledge Mobilization in the Real World - Seeking Wisdom}

When Aboriginal people speak of the red road, before acting one should always take their thinking from the mind, where it originates, carefully nurture the idea in our heart, and only then put it into practice in my experience, the wise ones, the elders, live this way. This could ensure that we are on the right path. My question, for our policy makers, for our politicians, for our leaders, for our administrators, for our practitioners, for our communities, for all of us who wish to serve, "Does our path have a heart?" As we develop new legislation, new policy, new standards, new ways of doing things, will we take the Red Road?

So, where do we go from here? I must confess that I do not have all of the answers. None of us do! However, I believe that between all of us together-clients, families, communities, front line staff, administrators, program planners, researchers and academics, policy makers, and politicians we do have all the answers.

We all have a different perspective depending on where we are. Nevertheless, none of us alone, like the blind men with the elephant, gets the whole picture. It is the same with the child welfare system. The only way that the blind men could begin to understand what an elephant looks like would have been to step back from it and describe to each other what they "see." It does not suffice to share each other's perspective and insist that it is the only valid one. We must be prepared to hear what others have to say if we are to understand their reality. This is the nub of the knowledge mobilization initiative in Alberta. It calls each of us to come together in a dialogue that can enrich the lives of our children, their families and their communities. If may seem complicated, but it does not have to be if we are but willing to be open to each other's truth.

\section{References}

Avison, W.R., Speechly, K.N., Thorpe, C.T., Gotlib, I.H., Rae Grant, N.I. \& Turner, J. (1994). Single parenthood, poverty, and the health of mothers and children: A stress process analysis. In M.W. Rosenberg (ed.), Health and Behaviour 1994: Papers and Proceedings. Kingston, ON: Queen's University.

Bassuk, E.L., Rubin, L. \& Lauriat, A. (1996). Characteristics of sheltered homeless families. American Journal of Public Health, 76, 1097 - 1101.

Bassuk, E.L., Buckner, J.C., Weinraub, L.F., Browen, A., Bassuk, S.S., Dawson, R. \& Perloff, J. (1997). Homelessness in female-headed families: Childhood and adult risk and protective factors. American Journal of Public Health, 87(2), 241 - 248.

Bennett, M. (2009). Jumping Through Hoops: A Manitoba Study Examining Experiences and Reflections of Aboriginal Mothers Involved with the Child Welfare and Legal Systems Respecting Child Protection Matters. Report prepared for Ka Ni Kanichihk Inc. and the Steering Committee of the Family Court Diversion Project. Winnipeg, MB: Ka Ni Kanichihk Inc. Available online from http://www.fncaringsociety.com/ projects/docs/FCDP_Final_Report_Bennett_2009.pdf.
Campbell, W. (Personal communication, December 2009).

Castenada, C. (1970). The Teachings of Don Juan: A Yaqui Way of Knowledge. Penguin Books.

Fuller, Buckminster from the Quotations page: http://www.quotationspage.com/quote/23586.html http://www.quotationspage.com/quote/34114.html

Galler, J.R., Ramsay, F., Solimano, G. \& Lowell, W. (1983). The influence of early malnutrition on subsequent behavioural development: II. Classroom behavior. Journal of the American Academy of Child Psychiatry, 22, 16 - 22.

Henderson, J.Y. (2000). Context of the State of Nature. In Reclaiming Indigenous Voice and Vision, Marie Battiste (Ed). Vancouver, BC: UBC Press.

Kinjerski, Valerie, and Margot Herbert. 2000. Welfare Caseload Growth in Alberta: Connecting the Dots. Unpublished Document. Available online at http://www.acsw.ab.ca/ publications/connecting the dots.zip/view.

Kowaleski-Jones, L. (1999). Welfare receipt and family structure: evaluating the effects on children's reading achievement. Sociological Focus, 32, 181-200.

Leschied, A.W. Chiodo, D. Whitehead, P. \& Hurley, D. (2003). The Association of Poverty with Child Welfare Service and Child and Family Clinical Outcomes. The University of Western Ontario. London, Ontario. Available online at http:// www.edu.uwo.ca/CAS/pdf/Child\%20Poverty $\% 20$ and $\% 20$ Child\%20Welfare\%20Admissions\%20Technical\%20Report.pdf.

Lindeman, E. C. (1948). Democracy and Social Work. Proceedings of the National Conference of Social Work. New York: Columbia University Press.

Pivot Legal Society. (February, 2009). Broken Promises: Parents Speak About B.C.'s Child Welfare System. Available online at http://www.pivotlegal.org/pdfs/BrokenPromises.pdf.

Saul, J.R. (1995). Voltaire's Bastards: The dictatorship of reason in the west. Toronto: Viking.

Understanding the Social Determinants of Health. (May, 2006). A discussion paper from the Office of the Chief Medical Officer, Vancouver Island Health Authority. Available online at http://www.crd.bc.ca/reports/regionalplanning/generalreports /housingaffordability /buildingthehousingaf /miscellaneous_understandingsociald/understanding_social_determinants_of health_05082006.pdf.

Wien, F., Blackstock C. Loxley, J., \& Trocmè, N. (2001). Keeping First Nations children at home: A few Federal policy changes could make a big difference. First Peoples Child \& Family Review, 3(1), 10-14. Available online at http://www.fncfcs. com/pubs/vol3num1/Wien_Blackstock_Loxley Trocme pp10.pdf.

Wilkinson, R. (2001). Mind the Gap: Hierarchies, Health and Human Evolution. Yale University Press.

Winslow, E. (1915). Philanthropic Individualism. Survey, 34, 555. 